\title{
Involvement of the cohesin protein, Smc1, in Atm-dependent and independent responses to DNA damage
}

\author{
Seong-Tae Kim, ${ }^{1,2}$ Bo Xu, ${ }^{1}$ and Michael B. Kastan ${ }^{3}$ \\ Department of Hematology-Oncology, St. Jude Children's Research Hospital, Memphis, Tennesee 38105-2794
}

\begin{abstract}
Structural maintenance of chromosomes (SMC) proteins play important roles in sister chromatid cohesion, chromosome condensation, sex-chromosome dosage compensation, and DNA recombination and repair. Protein complexes containing heterodimers of the Smc1 and Smc3 proteins have been implicated specifically in both sister chromatid cohesion and DNA recombination. Here, we show that the protein kinase, Atm, which belongs to a family of phosphatidylinositol 3-kinases that regulate cell cycle checkpoints and DNA recombination and repair, phosphorylates Smc1 protein after ionizing irradiation. Atm phosphorylates Smc1 on serines 957 and 966 in vitro and in vivo, and expression of an Smc1 protein mutated at these phosphorylation sites abrogates the ionizing irradiation-induced $S$ phase cell cycle checkpoint. Optimal phosphorylation of these sites in Smc1 after ionizing irradiation also requires the presence of the Atm substrates Nbs1 and Brca1. These same sites in Smc1 are phosphorylated after treatment with UV irradiation or hydroxyurea in an Atm-independent manner, thus demonstrating that another kinase must be involved in responses to these cellular stresses. Yeast containing hypomorphic mutations in SMC1 and human cells overexpressing Smc1 mutated at both of these phosphorylation sites exhibit decreased survival following ionizing irradiation. These results demonstrate that Smc1 participates in cellular responses to DNA damage and link Smc1 to the Atm signal transduction pathway.
\end{abstract}

[Key Words: SMC1; ATM; cell cycle checkpoints; ionizing irradiation]

Received December 18, 2001; revised version accepted January 7, 2002.

Signal transduction pathways activated by DNA damage and other cellular stresses are critical determinants of cell survival and cellular transformation. The product of the ATM gene, which is mutated in the cancer-prone disorder, Ataxia-telangiectasia (A-T), appears to be a major regulator of cellular responses to ionizing irradiation (Kastan and Lim 2000). Cells from A-T patients exhibit a variety of abnormalities, including genetic instability, radiosensitivity, cell cycle checkpoint defects in the $G_{1}$, $S$, and $G_{2}$ phases of the cell cycle, and poor growth in culture. Atm is a protein kinase that is activated by ionizing irradiation (Banin et al. 1998; Canman et al. 1998) and that phosphorylates a number of different substrates following activation, including p53, Mdm2, Chk2, Nbs1, Brca1, and Rad17 (Kastan and Lim 2000; Zhou and Elledge 2000; Shiloh and Kastan 2001). The functional consequences of some of these phosphorylation events

\footnotetext{
${ }^{1}$ These authors contributed equally to this work.

${ }^{2}$ Present address: Sungkyunkwan University School of Medicine, Samsung Biomedical Research Institute 300 Chunchun-Dong, Changan-Ku, Suwon, Kyunggi-Do 440-746, Korea.

${ }^{3}$ Corresponding author.

E-MAIL Michael.Kastan@stjude.org; FAX (901) 495-3966.

Article and publication are at http://www.genesdev.org/cgi/doi/10.1101/ gad.970602.
}

have been elucidated. For example, Atm phosphorylation of p53 (Banin et al. 1998; Canman et al. 1998), Chk2 (Matsuoka et al. 1998; Ahn et al. 2000; Melchionna et al. 2000; Zhou et al. 2000), and Mdm2 (Maya et al. 2001) appears to contribute to the arrest of cells in $\mathrm{G}_{1}$ following ionizing irradiation whereas phosphorylation of Nbs1, Brca1, and Rad17 is required for transient $S$ phase (Nbs1 and Brcal) or $\mathrm{G}_{2}$ (Brcal and Rad17) arrests after ionizing irradiation (Lim et al. 2000; Zhao et al. 2000; Bao et al. 2001; Xu et al. 2001). However, not all of the phenotypic abnormalities in A-T patients and cells from A-T patients can be explained by these known phosphorylation events, thus suggesting that there are likely additional targets of the Atm kinase that have not yet been identified.

Preliminary experiments demonstrated that the Smc1 protein was phosphorylated in an Atm-dependent manner following IR. The existing information about the roles of structural maintenance of chromosomes (SMC) proteins in chromatin and DNA dynamics made Smc1 a particularly interesting potential target of Atm to investigate further. The SMC genes were identified originally in Saccharomyces cerevisiae because they were required for proper condensation and segregation of mitotic chromosomes (Michaelis et al. 1997). This protein family 
turned out to be highly conserved across evolution, and members from lower and higher eukaryotes are now divided into four Smc protein subfamilies (Smc1-Smc4) and two Smc-like protein subfamilies (Smc5 and Smc6). The proteins appear to function as heterodimers with the Smc1-Smc3 heterodimer implicated in sister chromatid cohesion (also known as the cohesin complex) and the Smc2-Smc4 heterodimer implicated in chromosome condensation (also known as the condensin complex; Hirano 1999|. The Smc1-Smc3 heterodimer has also been found in a mammalian protein complex, called RC-1, that promotes DNA recombination (Jessberger et al. 1996; Stursberg et al. 1999|. The RC-1 complex, which appears to constitute only a minor fraction of the total Smc1-Smc3 complexes in normal cells (Strunnikov and Jessberger 1999|, promotes repair of gaps and deletions through recombination between otherwise homologous DNA molecules (Jessberger et al. 1993). DNA polymerase $\varepsilon$ and DNA ligase III have been reported to associate with this heterodimer (Strunnikov and Jessberger 1999), and the RC-1-mediated recombination and polymeraseligation reactions are stimulated by the single-stranded DNA-binding protein RPA (Jessberger et al. 1993).

Because of the functional links of Smcl to chromosome dynamics and to DNA recombination and the interest in identifying additional Atm substrates involved in cellular responses to ionizing irradiation, it was particularly attractive to investigate the possibility that Smc1 participated in an Atm-dependent signaling pathway. Here, we demonstrate that the Atm kinase phosphorylates Smcl on two sites in vitro and in vivo following exposure of cells to ionizing irradiation. These phosphorylation events appear to affect both the arrest of DNA replication and cell survival following irradiation. Phosphorylation of these sites in response to stresses other than ionizing irradiation in an Atm-independent manner and the observed hypersensitivity of yeast with diminished Smcl function to UV irradiation and hydroxyurea, suggest a role for Smcl protein in cellular stress responses that is not limited to ionizing irradiation. These data demonstrate for the first time that the essential gene product, Smc1, is involved in cellular responses to DNA damage and provide new potential directions for elucidating the phenotypic abnormalities observed in cells defective in Atm function.

\section{Results}

Smc1 is phosphorylated in an Atm-dependent manner following ionizing irradiation

As one approach to identify novel factors that interact with Atm, proteins that coimmunoprecipitate with Atm in large-scale extracts made from normal or A-T cells that had been exposed to 0 or $10 \mathrm{~Gy}$ of ionizing radiation were examined on silver-stained gels. A band of $\sim 160 \mathrm{kD}$ was noted to be present only in lysates from cells that had been irradiated and contained functional Atm (data not shown). This protein was eluted from the gel and identified as Smc1 protein by use of mass spectrometric peptide analysis techniques, and the identity was confirmed by Western blot analysis (data not shown). However, these Western blots demonstrated that the Smc1 protein was also present in immunoprecipitates from unirradiated cells and A-T cells, but was running with a different mobility in the extracts from irradiated normal cells (Fig. 1). Thus, Smcl was not specifically coimmunoprecipitating with Atm, but rather the novel band that had been observed in silver-stained gels was Smc1 protein with an altered mobility on the gels.

To identify the cause of the altered Smc1 mobility in irradiated cells, Smc1 protein that had been immunoprecipitated from irradiated cells was treated with a serine/ threonine phosphatase. This treatment increased the mobility of this protein in SDS-PAGE whereas cotreatment with a phosphatase inhibitor rescued the mobility shift, thus suggesting that the mobility shift resulted from phosphorylation of Smcl after ionizing irradiation (Fig. 1A). To test whether this phosphorylation was Atmdependent, the mobility shift of Smcl was examined in two normal cell lines and two cell lines from patients with ataxia-telangiectasia (A-T). Although Smc1 in irradiated normal cells was efficiently phosphorylated, Smcl in Atm-deficient lymphoblasts and fibroblasts was not phosphorylated after ionizing irradiation (Fig. 1B). Complementation of A-T cells with a full-length ATM

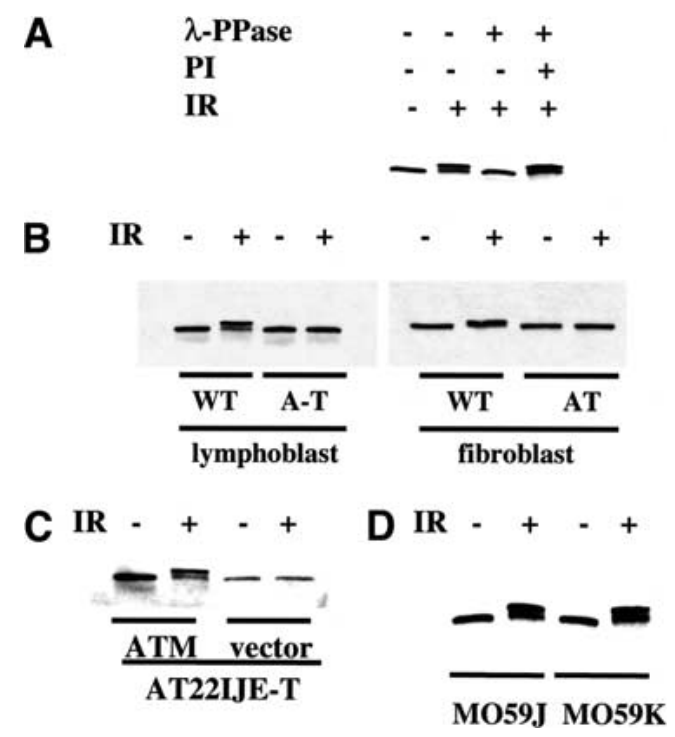

Figure 1. Smc1 is phosphorylated in an Atm-dependent manner after ionizing irradiation. $(A)$ Ionizing irradiation-induced Smcl modification is caused by serine/threonine phosphorylation. Smc1 immunoprecipitates from unirradiated or irradiated (10 Gy) normal lymphoblast cells (GM0536) were incubated with either lambda phosphatase ( $\lambda$-PPase) alone or with $\lambda$-PPase and phosphatase inhibitor (PI). (IR) Ionizing irradiation. $(B-D)$ Immunoblot analyses for $\mathrm{Smcl}$ protein $1 \mathrm{~h}$ after exposure to 0 $(-)$ or $10(+)$ Gy of ionizing irradiation in lymphoblasts [GM0536 (WT) and GM01526 (A-T)] or SV40-transformed fibroblasts [GM0637 (WT) and GM09607 (AT)] (B); A-T fibroblasts (AT22IJE-T) transfected with vector alone or with a full-length ATM cDNA (ATM) (C); or DNA-PK-deficient cells (M059J) and DNA-PK-proficient cells (M059K) (D). 
cDNA restored the phosphatase-sensitive mobility shift after irradiation (Fig. 1C). Therefore, functional Atm is required for the ionizing irradiation-induced phosphorylation of Smc1.

Though Atm is required for efficient phosphorylation of Ser 15 of p53 after ionizing irradiation, this site does eventually become phosphorylated after ionizing irradiation even in cells lacking Atm, presumably by the related kinase, Atr (Siliciano et al. 1997; Canman et al. 1998; Tibbetts et al. 1999). In contrast, no phosphorylation of the Smc1 protein was detected in A-T cells up to $6 \mathrm{~h}$ after exposure to $10 \mathrm{~Gy}$ of ionizing irradiation (data not shown). This finding suggests that the mechanism of Smc1 phosphorylation after ionizing irradiation is defective in A-T cells. Ionizing irradiation-induced phosphorylation of Smcl was evident in cells lacking the DNA-dependent protein kinase catalytic subunit (DNAPKcs), thus indicating that unlike Atm, DNA-PKcs is not required for ionizing irradiation-induced phosphorylation of Smcl in vivo (Fig. 1D). These results suggest that ionizing irradiation induces the Atm-dependent phosphorylation of a serine/threonine residue(s) in Smc1 and raise the possibility that $\mathrm{Smcl}$ is a direct physiological substrate for Atm in vivo after ionizing irradiation.

\section{Smc1 is an in vitro target of Atm kinase}

To investigate whether Atm directly phosphorylates Smcl after treatment with ionizing irradiation, the ability of Atm to phosphorylate Smcl protein in vitro was examined. The requisite target sequence for phosphorylation by Atm is a serine or a threonine followed by a glutamine residue (Kim et al. 1999; O'Neill et al. 2000), and Smc1 contains seven SQ sites and two TQ sites. Glutathione-S-transferase (GST)-conjugated peptides containing 14-amino-acid peptide fragments of Smc1 surrounding the various SQ/TQ sites were generated as substrates for in vitro kinase reactions with Atm. A GST-p53 peptide served as a positive control and was efficiently phosphorylated by wild-type Atm (Fig. 2A, lane 2), but not by kinase-dead Atm (Fig. 2A, lane 1). Three GST-Smc1 peptides (amino acids 353-366, 951964, and 960-973) were good in vitro substrates for the wild-type Atm kinase (Fig. 2A, lanes 4,9,10).

Larger GST-Smc1 peptides containing 82 or 100 amino acids surrounding serines 358 and 360 or serines 957 and 966 (amino acids 301-382 and 901-1000) were then evaluated in these kinase assays. GST-Smc1 (amino acids 301-382) was minimally phosphorylated by Atm (Fig. 2B, lane 2), whereas GST-Smcl (amino acids 901-1000) was an excellent in vitro substrate for Atm (Fig. 2B, lane 6). Mutation of either Ser 957 or Ser 966 to alanine in the target GST-Smc1 (amino acids 901-1000) each partially abrogated the phosphorylation of the conjugated peptide by Atm (Fig. 2B, lanes 7,8), whereas mutation of Ser 957 and Ser 966 in combination completely eliminated phosphorylation by Atm (Fig. 2B, lane 9). These findings suggest that Ser 957 and Ser 966 are two major target sites of in vitro phosphorylation by Atm.

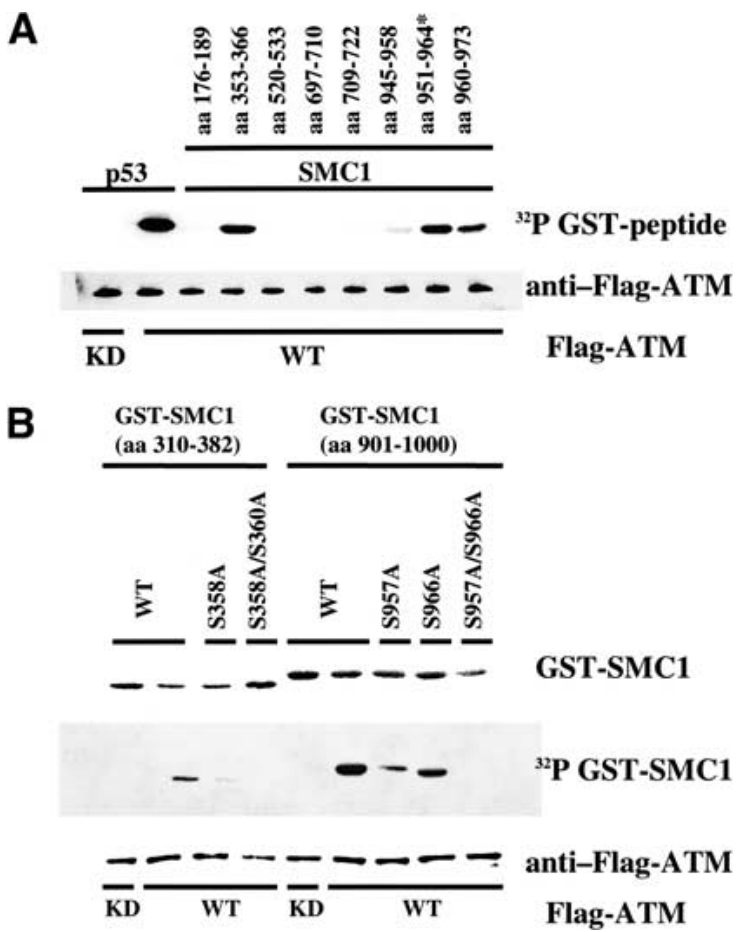

Figure 2. Serine 957 and Serine 966 are the two major residues of Smcl that are phosphorylated by Atm in vitro. $(A)$ Immunoprecipitated wild-type (WT) Flag-tagged Atm or kinase-dead (KD) Flag-tagged Atm were incubated with recombinant proteins consisting of fusions between GST and peptides derived from various regions of human Smcl. The positions of the amino acids corresponding to each peptide are indicated at the top. A p53 peptide (amino acids 9-21) was used as a positive control. $\left(^{*}\right)$ Serine 951 was changed to alanine. (B) Atm phosphorylation of large fragments of Smc1 and mutation of relevant serines.

Smc1 is phosphorylated on both Ser 957 and Ser 966 in response to DNA damage

To investigate whether the Atm kinase phosphorylates Ser 957 or Ser 966 of Smc1 in response to ionizing irradiation in vivo, rabbit polyclonal antibodies that specifically recognize $\mathrm{Smcl}$ when these serines are phosphorylated were generated. The specificity of each phosphospecific antibody was illustrated by its ability to recognize a peptide sequence surrounding the target serine when it is phosphorylated, but not when it is unphosphorylated (Fig. 3A). These polyclonal antisera were specific for one phosphopeptide and did not cross-react with the other phosphopeptide. To investigate whether Ser 957 or Ser 966 is phosphorylated in vivo and whether any such phosphorylation event is Atm dependent, we examined the phosphorylation of these two residues in endogenous Smc1 in transformed fibroblasts from a normal individual (GM0637) and from a patient with A-T (GM 9607). Both the anti-S957-p antibody (Fig. 3B, top) and the anti-S966-p antibody (Fig. 3B, middle), bound to Smcl protein only in irradiated cells containing wildtype Atm. No phosphorylation of Smcl was observed in unirradiated normal or A-T cells or in irradiated A-T 
A

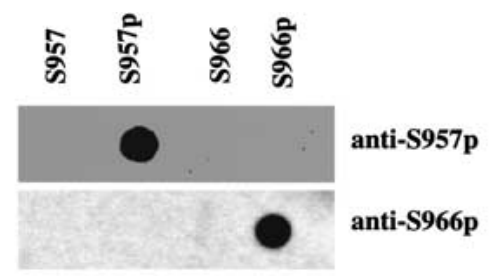

B

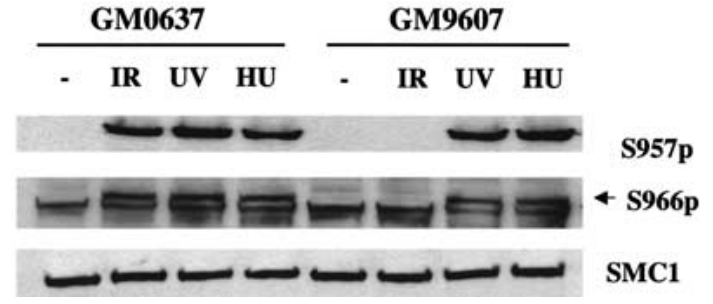

Figure 3. Atm-dependent and -independent phosphorylation of Smcl on Ser 957 and Ser 966 in vivo. (A) Immunoblots probing $50 \mathrm{ng}$ of phosphorylated or unphosphorylated synthetic peptides using rabbit polyclonal antibodies raised against peptides containing Ser 957-p or Ser 966-p. (B) Immunoblot analyses using the two phosphoserine-specific antibodies (top and middle) or an anti-SMC1 antibody (K1; bottom) on SMC1 protein from normal (WT; GM0637) or A-T (GM9607) fibroblasts treated with ionizing irradiation (IR; $10 \mathrm{~Gy}, 2 \mathrm{~h})$, ultraviolet light (UV; $\left.50 \mathrm{Jm}^{-2}, 2 \mathrm{~h}\right)$ or hydroxyurea (HU; $\left.1 \mathrm{mM}, 24 \mathrm{~h}\right)$. The arrow (middle) points to the band specifically recognized by the antiphosphoserine 966 antibody (note a nonspecific band runs just below the S966-p band).

cells. No changes in the levels of Smcl protein were seen after ionizing irradiation. Similarly, lymphoblastoid cells demonstrated the same Atm-dependent phosphorylation of serines 957 and 966 in response to ionizing irradiation (data not shown). These results demonstrate that Smc1 is phosphorylated on Ser 957 and Ser 966 in an Atm-dependent manner in response to ionizing irradiation.

Post-translational modification of Smc1 protein in response to other cellular stresses was also examined. Exposure of cells to ionizing irradiation, ultraviolet (UV) irradiation or the DNA replication inhibitor hydroxyurea (HU), all caused reduced mobility of Smcl protein in SDS-PAGE (Fig. 3B) and resulted in reactivity with the anti-S957-p and anti-S966-p antibodies (Fig. 3B). In contrast to the Atm-dependence for Smcl phosphorylation after ionizing irradiation, $\mathrm{UV}$ and $\mathrm{HU}$ treatment induced Ser 957 and Ser 966 phosphorylation even in A-T cells. These findings indicate that another kinase, potentially the Atr kinase, can phosphorylate these serines in Smc1 in response to other types of DNA damage or replication blockade.

\section{Phosphorylation of Smc1 does not affect binding to Smc3}

The functional consequences of these phosphorylation events for cellular responses to ionizing irradiation were then explored. Previous characterization of Smcl has demonstrated that $\mathrm{Smc1}$ forms a heterodimer with the Smc3 protein (Losada et al. 1998). Most of these heterodimers are found in the cohesin complex, which is important for sister chromatid cohesion, but a fraction of the Smc1-Smc3 heterodimers have also been found in a mammalian recombination complex (RC-1; Jessberger et al. 1996). To test whether Atm-dependent phosphorylation of serines 957 and 966 of Smcl affects the interaction between Smc1 and Smc3, vectors that express Myctagged Smc1 (either wild type or mutated at Ser 957 or Ser 966 or both) were co-transfected with HA-tagged Smc3 into 293T cells, and the proteins were evaluated for co-immunoprecipitation with and without cellular irradiation. It is notable that the mutant Smcl proteins were expressed at levels similar to the wild-type protein (Fig. 4B,C). Immunoprecipitation with an anti-Myc antibody brought down HA-Smc3 whether it had been cotransfected with wild-type Smc1 or mutant Smc1 genes

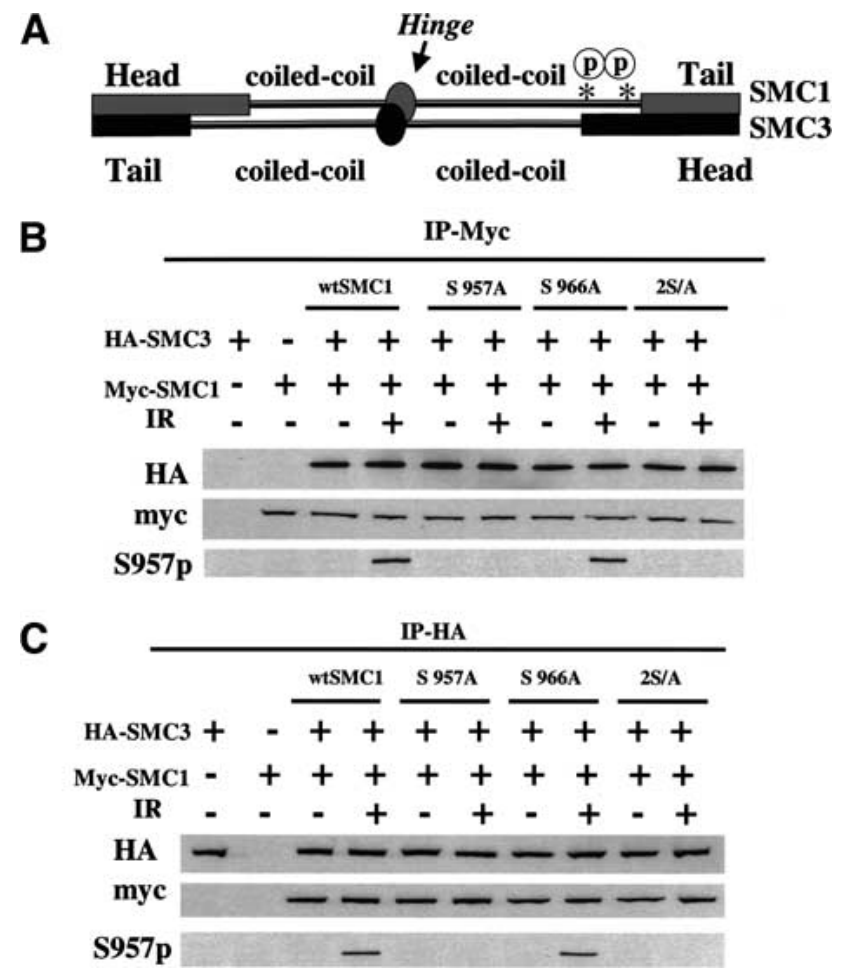

Figure 4. Phosphorylation of Smcl does not inhibit the binding of Smc1 to Smc3. (A) Schematic representation of the domains of Smc1 bound to Smc3 illustrating the approximate location of the Smc1 Ser 957 and Ser 966 sites with the asterisk. (B) Two hours after exposure to $0(-)$ or $10(+)$ Gy of ionizing irradiation (IR), Myc-tagged proteins were immunoprecipitated from 293T cells that had been cotransfected with Myc-tagged SMC1 (wild type, S957A, S966A, 2S/A) and HA-tagged SMC3. The proteins were immunoblotted either with anti-Myc antibody, anti-HA antibody, or anti-S957-p antibody. (C) Two hours after exposure to $0(-)$ or $10(+)$ Gy of ionizing irradiation, HAtagged proteins were immunoprecipitated from 293T cells that had been cotransfected with Myc-tagged SMC1 (wild type, S957A, S966A, 2S/A) and HA-tagged SMC3. The proteins were immunoblotted either with anti-HA antibody, anti-Myc antibody, or anti-S957-p antibody. 
and regardless of irradiation status (Fig. 4B, middle). Similarly, immunoprecipitation with an anti-HA antibody brought down Myc-tagged Smc1 proteins, regardless of the status of serines 957 and 966 and regardless of the irradiated status of the cells (Fig. 4C). Specifically, the phosphorylated form of Smc1 was coimmunoprecipitated with Smc3 from the irradiated cells (Fig. 4C, bottom). It is notable that the anti-S957-p antibody recognized wild-type Smc1 and S967A Smc1 from irradiated cells, but did not recognize the S957A mutant of Smc1 (Fig. 4B,C), thus demonstrating further the specificity of the anti-S957-p antibody. These data demonstrate that Atm phosphorylation does not block the heterodimerization of Smc1 and Smc3.

\section{Phosphorylation of Smc1 is required}

for the IR-induced S-phase checkpoint

In mammalian cells, cohesin links two sister chromatids during $\mathrm{S}$ phase, and most of these links are dissociated at the onset of mitosis (Losada et al. 1998). Because Smc1 is important for progression through the cell cycle, we tested whether phosphorylation of this protein could be important during cell cycle perturbations after DNA damage. Mammalian cells lacking Smc1 protein, which would be ideal for complementation studies to investigate the functional ramifications of Smcl phosphorylation, are not currently available and would likely be nonviable. Therefore, the possibility that overexpression of an Smcl protein mutated at the Atm phosphorylation sites might act in a dominant-negative manner to inhibit the normal function of endogenous Smc1 was investigated. First, the transient inhibition of DNA synthesis after exposure to ionizing irradiation in cells expressing wild-type Smc1 or mutant Smcl was assessed. 293T cells transiently transfected either with an empty vector or with wild-type Smcl exhibited a normal ionizing irradiation-induced S-phase arrest. In contrast, $293 \mathrm{~T}$ cells transiently transfected with vectors expressing Smc1 containing a S957A mutation, a S967A mutation, or both mutations all exhibited substantially impaired $S$ phase arrests after ionizing irradiation (Fig. 5A). Expression of these mutant constructs affected only the DNA replication after irradiation and had no discernible effects on the basal measurements of DNA replication. The effects of transfecting these expression vectors encoding wildtype Smc1 or S957A mutant Smc1 into A-T heterozygote (GM0637) or A-T homozygote (GM09607) SV40-transformed fibroblasts was also examined. The A-T heterozygote cells have a normal $S$ phase arrest after IR, but introduction of the Smcl mutants abrogated this checkpoint (data not shown). Thus, overexpression of the mutant Smcl constructs caused a defect in the S phase checkpoint in two different cell types. The A-T homozygote cells lacked the S phase checkpoint, as expected, and introduction of either wild-type or mutant Smc1 did not alter this phenotype (data not shown).

Though overexpression of the mutant Smc1 constructs abrogated the ionizing irradiation-induced S phase checkpoint in $293 \mathrm{~T}$ cells and SV40-transformed fibroblasts, this mutant did not affect the ionizing irradiation-induced $\mathrm{G}_{2} / \mathrm{M}$ checkpoint (Fig. $5 \mathrm{~B}$ ). As a positive control, transfection of a dominant-negative construct of ATM caused the expected loss of the ionizing irradiation-induced $\mathrm{G}_{2} / \mathrm{M}$ checkpoint (Fig. 5B). Because the mutant Smc1 constructs blocked the Atm-dependent $\mathrm{S}$ phase checkpoint, but did not alter the Atm-dependent $\mathrm{G}_{2} / \mathrm{M}$ checkpoint (using the same batch of transfected cells for the two experiments), these constructs are not nonspecifically blocking Atm function. Rather, they appear to be specifically affecting the $S$ phase checkpoint pathway.

We demonstrated recently that two molecularly distinct $\mathrm{G}_{2}$ arrests are induced by exposure of cells to ionizing irradiation (Xu et al. 2002). An early and transient $\mathrm{G}_{2}$ arrest occurs that is dependent on Atm and Brcal and represents cells that were in $G_{2}$ at the time of irradiation and that then fail to enter mitosis for a period of time after irradiation. In contrast, accumulation of cells with 4N content DNA is measured at later times after irradiation, is independent of Atm and Brcal, and represents cells that enter $G_{2}$ after having been irradiated in $S$ phase or earlier in the cell cycle. This latter arrest is more pronounced in cells that lack the ionizing irradiationinduced $S$ phase checkpoint, perhaps because failure to appropriately arrest in $S$ phase after ionizing irradiation results in a need to arrest for a prolonged period of time in $G_{2}$. Because expression of the phosphorylation site mutant constructs of Smc1 inhibited the ionizing irradiation-induced S phase checkpoint (Fig. 5A), this model would predict that these dominant-negative constructs would also cause enhanced accumulation of cells in $G_{2}$ at later times after ionizing irradiation. Thus, we examined accumulation of transiently transfected cells in $\mathrm{G}_{2}$ after ionizing irradiation over time. Compared with $293 \mathrm{~T}$ cells transfected with vector control or with wildtype SMC1, cells transfected with any of the phosphorylation site mutant SMC1 constructs exhibited prolonged $\mathrm{G}_{2}$ accumulation (Fig. $5 \mathrm{C}$ ). These results are consistent with the concept that lack of the IR-induced S phase checkpoint results in enhanced accumulation of cells in $\mathrm{G}_{2}$ over time after ionizing irradiation. Thus, phosphorylation of Smc1 by Atm does not seem to be required for the immediate arrest of cells in the $G_{2}$ phase of the cycle (Fig. 5B), but these modifications do have an effect on $\mathrm{G}_{2}$ accumulation (Fig. 5C) because of their importance in $S$ phase arrest after ionizing irradiation.

\section{The role of Smc1 in modulating radiation sensitivity}

Smcl protein has been functionally linked to the processes of sister chromatid cohesion and DNA recombination (Strunnikov and Jessberger 1999). However, it had not been previously linked to cellular responses to DNA damage. Our results have demonstrated that Smc1 protein is involved in an Atm-related DNA damage response pathway and have implicated its phosphorylation by Atm in the control of the ionizing irradiation-induced $S$ phase checkpoint. Because yeast mutants lacking Smcl protein are not viable (Strunnikov and Jessberger 
1999) and Smc1-null mammalian cells are not available and would likely be nonviable, we turned to a temperature-sensitive yeast smc1 mutant to demonstrate further the principle that this protein is important in DNA damage responses. The smc1-259 mutant of S. cerevisiae (Michaelis et al. 1997) grows well at the permissive tem-

A

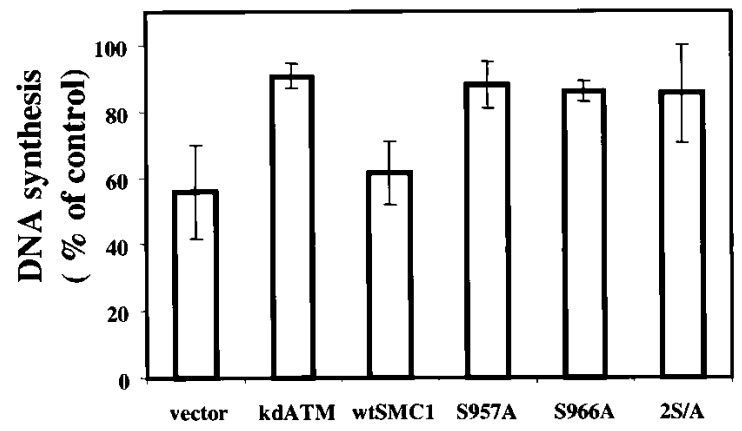

B

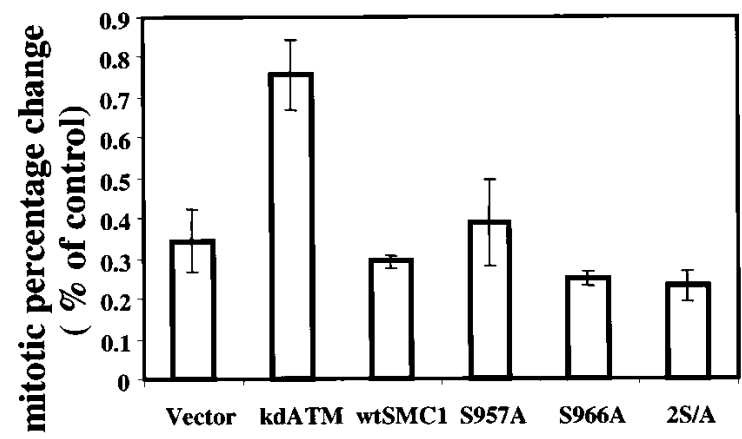

C

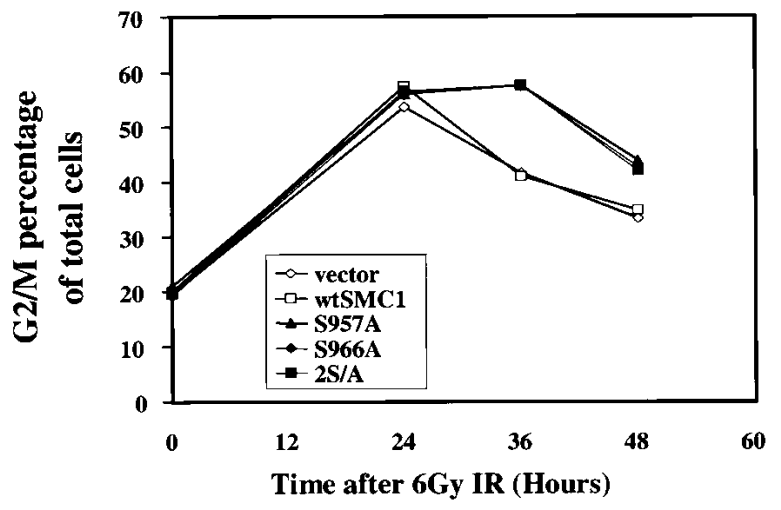

$\mathbf{D}$

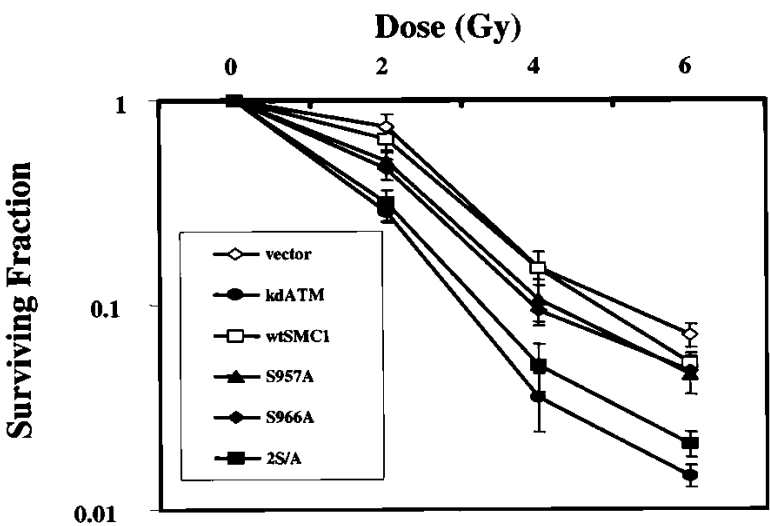

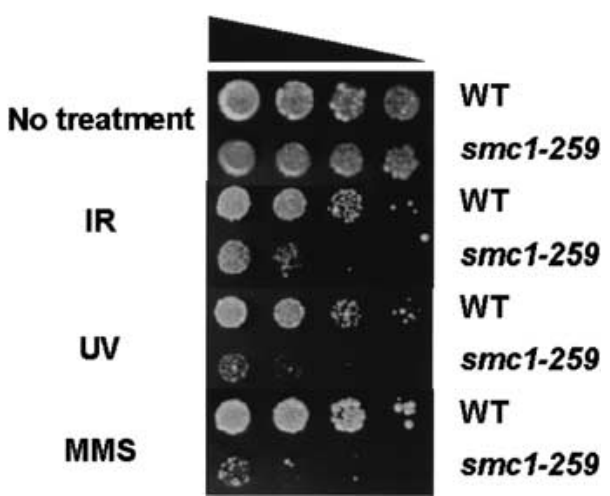

Figure 6. Smcl protein is important for DNA damage responses in yeast. Wild-type or smc1-259 mutant yeast were serially diluted by tenfold amounts and plated on YPD media at $30^{\circ} \mathrm{C}$ with or without $0.02 \%$ of methymethane sulfonate (MMS). Cells on plates were treated with ionizing irradiation (200 Gy) or ultraviolet light (UV; $50 \mathrm{Jm}^{-2}$ ).

perature of $25^{\circ} \mathrm{C}$, but loses some Smcl function at the semipermissive temperature of $30^{\circ} \mathrm{C}$. This mutant showed marked hypersensitivity to ionizing irradiation, UV, and methylmethane sulfonate (MMS) treatment (Fig. 6). Because the yeast Smcl protein does not contain the Ser 957 and Ser 966 sites that are the targets of Atm phosphorylation in human cells, this system is not amenable to studies that investigate these particular phosphorylation events. Nevertheless, because these yeast cells have mutated SMC1 genes, this result definitively confirms the novel finding that Smcl protein is important for DNA damage responses in eukaryotic cells.

Figure 5. Mutation of the Atm phosphorylation sites on Smc1 results in an $\mathrm{S}$ phase checkpoint defect and radiosensitivity. $(A)$ $293 \mathrm{~T}$ cells transiently transfected with empty vector or wildtype (WT) or mutant (S957A, S966A, or 2S/A) of SMC1 were assessed for inhibition of DNA synthesis $30 \mathrm{~min}$ after exposure to $10 \mathrm{~Gy}$ of ionizing irradiation. (Error bars) Average of at least triplicate samples. $(B)$ Ionizing irradiation-induced $\mathrm{G}_{2} / \mathrm{M}$ checkpoint: The mitotic percentage change of $293 \mathrm{~T}$ cells transfected with empty vector, wild-type (WT), or mutant (S957A, S966A, or 2S/A) SMC1 or kinase-dead ATM (kdATM) 90 min after 6 Gy of ionizing irradiation is shown. Mitotic cell percentage was determined by anti-phosphohistone $\mathrm{H} 3$ staining followed by flow cytometric analysis. (Error bars) Average of at least triplicate samples. $(C)$ Ionizing irradiation induced $\mathrm{G}_{2}$ accumulation: $293 \mathrm{~T}$ cells transfected with empty vector, wild-type (WT), or mutant (S957A, S966A or 2S/A) SMC1 were irradiated at 6 Gy, and cell cycle distribution after ionizing irradiation in the indicated time points was assessed by propidium iodide staining. $\mathrm{G}_{2} / \mathrm{M}$ percentage of total cells was shown. All results are representative samples of three different experiments. $(D)$ Expression of Smcl phosphorylation-site mutants increases radiosensitivity. HeLa cells expressing either empty vector, wild-type (WT), or mutant (S957A, S966A, or 2S/A) constructs of SMC1 or kinase-dead ATM (kdATM) were exposed to 0-6 Gy of ionizing irradiation and incubated for 1 week prior to fixation, staining, and assessment of colony formation. The clonogenic survival assays were performed in triplicate. Error bars indicate S.E. 
To more specifically investigate the potential role of these phosphorylation sites in modulating radiation sensitivity, we evaluated the clonogenic survival of HeLa cells that had been transfected with vector control, wildtype SMC1, or phosphorylation site mutants of SMC1. The cells expressing Smc1 that had been mutated at either Ser 957 or Ser 966 alone showed a moderate increase in radiosensitivity compared with cells transfected with control vector or wild-type SMC1 (Fig. 5D). HeLa cells expressing the Smc1 construct that was mutated at both phosphorylation sites were even more radiosensitive, very closely approximating the radiosensitivity of cells transfected with a dominant-negative construct of ATM (Fig. 5D). Thus, the yeast data demonstrate that Smc1 function is an important determinant of cell survival following DNA damage or replication arrest, and the results with the transfected HeLa cells extend this concept to suggest that the Atm target sites are important for cell survival following irradiation in mammalian cells.

\section{Brca1 and Nbs1 are required for Smc1 phosphorylation following ionizing irradiation}

Though the previous data linked Smcl to cellular responses to ionizing irradiation in general and demonstrated it to be a target of the Atm kinase specifically, it was not clear how Smcl and these phosphorylation events relate to the other previously identified Atm targets. To begin to explore this issue, the phosphorylation of Smc1 was evaluated in cells with mutated Nbs1 or Brcal genes. Though phosphorylation of both Ser 957 and Ser 966 was easily detected after ionizing irradiation in an SV40-transformed fibroblast line containing wildtype Atm, Brca1, and Nbs1, phosphorylation of both sites was below the level of detection in cells lacking functional Atm (GM9607), Nbs1 (NBS1-LB1), or Brca1 (HCC1937) (Fig. 7A). Because the HCC1937 cells are a tumor cell line and could have other genetic alterations affecting this pathway, it was necessary to demonstrate complementation of these ionizing irradiation-induced phosphorylation events with reintroduction of Brcal into these cells to definitively implicate Brcal in this process. Transient transfection of wild-type Brcal into the HCC1937 cells restored detectable ionizing irradiation-induced phosphorylation of both Ser 957 and Ser 966 (Fig. 7B). We demonstrated previously that transfection of a construct encoding Brcal mutated at Ser 1387 complements the $\mathrm{G}_{2}$ checkpoint, but not the $S$ phase checkpoint whereas transfection of a construct encoding Brcal mutated at Ser 1423 complements the S phase checkpoint, but not the $\mathrm{G}_{2}$ checkpoint (Xu et al. 2001; B. $\mathrm{Xu}, \mathrm{A}$. O'Donnell, S. Kim, and M. Kastan, in prep.). It is notable that both of these mutants complement the radiosensitivity of HCC1937 cells even though these cells still lack one or the other of these ionizing irradiationinduced cell cycle checkpoints (Xu et al. 2002). Introduction of either of these mutated forms of Brcal also complemented the ionizing irradiation-induced phosphorylation of Smc1 (Fig. 7B). Thus, optimal phosphorylation of Smc1 at these sites is dependent on the pres-
A

\section{A}

GM0637 GM9607 NBS1-LBI HCC1937

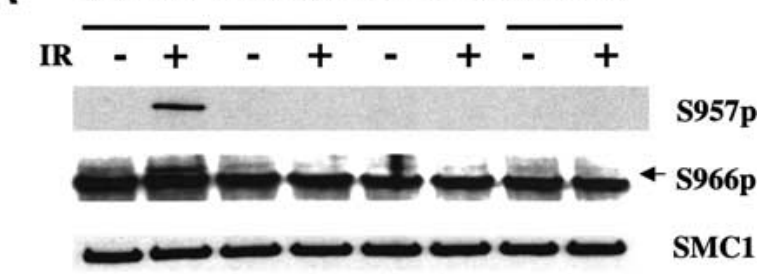

B

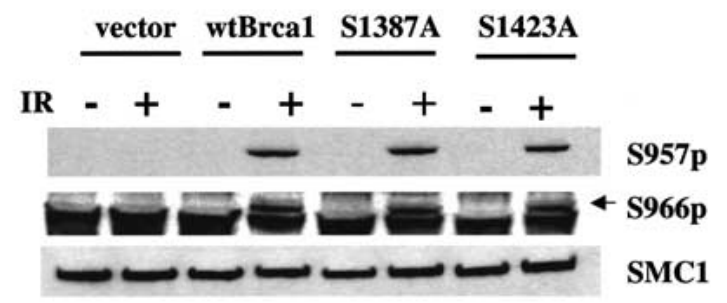

C

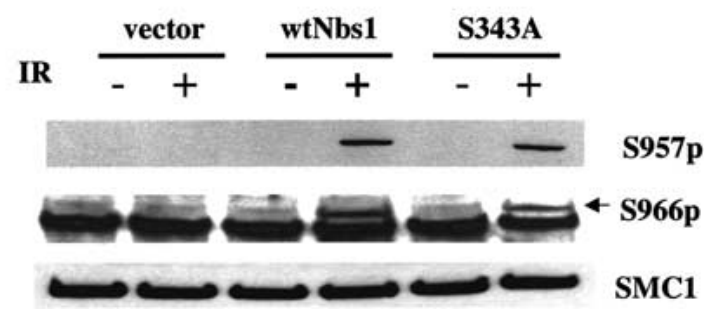

Figure 7. Brcal and Nbs1 are required for optimal ionizing irradiation-induced Smcl phosphorylation. (A) Smc1 phosphorylation on Ser 957 and Ser 966 is defective in cells with mutated Atm, Nbs1, or Brcal genes: Smc1 phosphorylation was assessed by immunoblot analyses using the two phosphoserinespecific antibodies (top and middle) or an anti-Smcl antibody (K1; bottom panel) in normal (GM0637), Atm-deficient (GM9607), Nbs1-deficient (NBS1-LBI), and Brca1-deficient (HCC1937) cell lines. (Arrows) Specific S966-p band. (B) Introduction of Brcal into HCC1937 cells restores effective ionizing irradiation-induced Smc1 phosphorylation. Smcl phosphorylation was assessed in HCC1937 cells that had been transiently transfected with wild-type BRCA1 (wtBrcal) or mutant [serine 1387 to alanine substitution (S1387A) or serine 1423 to alanine substitution (S1423A)] Brcal constructs. (C) Introduction of NBS1 into NBS cells restores effective Smc1 phosphorylation. Smcl phosphorylation was assessed in NBS cells that had been stably transfected with wild-type NBS1 (wtNbs1) or mutant [serine 343 to alanine substitution (S343A)].

ence of a Brcal protein, but is not dependent on whether or not the $S$ phase or $G_{2}$ checkpoints have occurred.

Similar results were obtained with complemented NBS cells. NBS fibroblasts that had been stably transfected with wild-type Nbs1 recovered the ionizing irradiation-induced phosphorylation of Smcl on both of these serines (Fig. 7C). Introduction of Nbs1 protein mutated at the Atm target site, Ser 343, into these cells complements radiosensitivity, but does not complement the ionizing irradiation-induced S phase checkpoint (Lim et al. 2000; Xu et al. 2002). NBS cells expressing the Ser 343 mutant also recovered the ionizing irradiation-induced phosphorylation of Smcl on both of these Atm targets (Fig. 7C). These results demonstrate further that though Smc1 phosphorylation appears to be required for 
the ionizing irradiation-induced S phase checkpoint, the ionizing irradiation-induced $S$ phase checkpoint is not required for the phosphorylation of Smc1. However, the presence of some form of Nbsl and Brcal proteins appears to be required for Atm to optimally phosphorylate Smcl on these sites after ionizing irradiation.

\section{Discussion}

Elucidation of cellular responses to DNA damage at the molecular level can provide important insights into mechanisms involved in both cancer causation and responses of tumors to therapeutic interventions. For example, linking the p53 protein to cellular responses to DNA damage (Kastan et al. 1992) and other cellular stresses (Graeber et al. 1996) has had a major impact on models of tumor development involving p53 mutations and on studies evaluating tumor responses to therapy based on the presence or absence of p53 mutations (Vogelstein et al. 2000). Similarly, the Atm protein kinase, which is a critical regulator of cellular responses to ionizing irradiation, is both a tumor suppressor gene product and a potential target for radiosensitizing tumors (Shiloh and Kastan 2001). Several targets of the Atm kinase that are involved in cellular responses to ionizing irradiation have been characterized previously, including p53, Chk2, Mdm2, Nbs1, and Brcal (Kastan and Lim 2000). In this report, we add the essential chromosomal protein, Smc1, to the list of bona fide Atm targets and demonstrate that it plays a role in the ionizing irradiation-induced S phase checkpoint and in modulation of radiosensitivity.

Serines 957 and 966 in Smcl were identified as the primary targets of Atm in vitro and use of phosphoserine-specific antibodies demonstrated that these same two sites are also phosphorylated in cells following ionizing irradiation in an Atm-dependent manner. Interestingly, these same two sites are phosphorylated following treatment of cells with UV irradiation or hydroxyurea, but following these treatments, the phosphorylation does not require the Atm kinase. The lack of requirement for Atm following these treatments is not surprising as Atm appears to be relatively specifically involved in responses to DNA strand breaks and not in response to other cellular stresses (Kastan and Lim 2000). Similar observations have been made with other Atm targets, like p53, where phosphorylation following UV irradiation is independent of Atm (Siliciano et al. 1997). In the case of p53 phosphorylation following UV irradiation, the Atr kinase, which has a consensus target sequence that is similar to that of Atm (Kim et al. 1999), has been implicated (Tibbetts et al. 1999). Similarly, the kinase responsible for Smcl phosphorylation at these serines following UV and hydroxyurea treatment seems likely to be Atr, but this remains to be formally demonstrated.

Though Smcl has been implicated in processes involved in chromosomal and DNA dynamics, in particular chromosome cohesion and DNA recombination (Strunnikov and Jessberger 1999), it has not been linked previously to cellular responses to DNA damage. Be- cause of its critical role in chromosome cohesion, yeast lacking Smcl are nonviable (Strunnikov and Jessberger 1999|. However, we found that yeast with hypomorphic SMC1 alleles exhibit increased sensitivity to three different DNA damaging agents. Thus, a role for Smc1 in DNA damage responses appears to span the evolutionary spectrum at least from yeast to man. The damage-induced phosphorylation sites are found in human and mouse Smc1, but are not present in the yeast gene, thus suggesting that the regulation of Smcl by these phosphorylation events has arisen more recently in evolution.

Phosphorylation of these sites appears to be involved in both the ionizing irradiation-induced S phase checkpoint and in modulating radiosensitivity. However, the mechanisms by which Smcl phosphorylation influences these processes remain to be worked out. The role of Smcl in chromosome cohesion raised the interesting possibility that lack of its phosphorylation may play a role in the enhanced chromosome breakage seen in A-T cells after ionizing irradiation and that this may be responsible for the radiosensitivity in A-T cells. However, though transfection of the Smcl construct mutated at both phosphorylation sites induces radiosensitivity (Fig. $6 \mathrm{~B})$, it does not cause a measurable increase in ionizing irradiation-induced chromosomal breakage /data not shown). This result separates out the radiosensitivity phenotype from the chromosomal breakage phenotype. In addition, the induction of Smcl phosphorylation of these same sites following hydroxyurea treatment suggests that cells signal to Smcl in response to arrest of DNA replication. The functional ramifications of Smc1 phosphorylation in this pathway have not been elucidated. Another intriguing potential link of Smc1 function to radiosensitivity relates to its apparent role in DNA recombination via its presence in the RC-1 complex (Jessberger et al. 1996; Stursberg et al. 1999). Whether phosphorylation of Smc1 by Atm affects its function in recombination events needs to be explored.

The mechanistic link between Atm phosphorylation of serines 957 and 966 of Smc1 and blockade of replication fork initiation following ionizing irradiation also remains to be made. Recent data has suggested that Chk2 phosphorylation of Cdc25A in the ionizing irradiation-induced arrest is the link between Atm and the replication machinery via effects on Cyclin E/Cdk2 activity (Falck et al. 2001). However, this model alone does not explain the apparent requirements for Atm-induced phosphorylation of Nbs1, Brca1, and Smc1 proteins in this process. Perhaps the situation is analogous to the Atm-dependent $G_{1}$ checkpoint in which Atm apparently simultaneously phosphorylates multiple proteins (p53, Chk2, and $\mathrm{Mdm} 2$ ) to cause the arrest (Kastan and Lim 2000). In the case of the ionizing irradiation-induced S phase checkpoint, Atm may simultaneously phosphorylate Chk2, Nbs1, Brca1, and Smc1 after activation by ionizing irradiation (Fig. 8). It is quite conceivable that two or more pathways act in concert to cause $S$ phase arrest after ionizing irradiation and that the Chk2Cdc25A-CyclinE/Cdk2 steps do not involve these other 
Figure 8. Schematic representation of direct targets of ATM that affect cell cycle perturbations and modulation of sensitivity to ionizing irradiation. Following ionizing irradiation, the Atm protein kinase is activated and then phosphorylates target proteins. The exact serines (S) or threonine (T) known to be phosphorylated by Atm are listed by number for the various proteins. Chk2, p53, and $\mathrm{Mdm} 2$ participate in the $\mathrm{G}_{1}$ arrest, phosphorylation of Nbs1, Brca1, Smc1, and Chk2 have been implicated in controlling the $\mathrm{S}$ phase arrest, and phosphorylation of Brcal and Rad17 are reported to be involved in the $\mathrm{G}_{2}$ arrest. Although phosphorylation of Chk2 has been reported to be dependent on Nbs1 (Buscemi et al. 2001), the exact relationship of

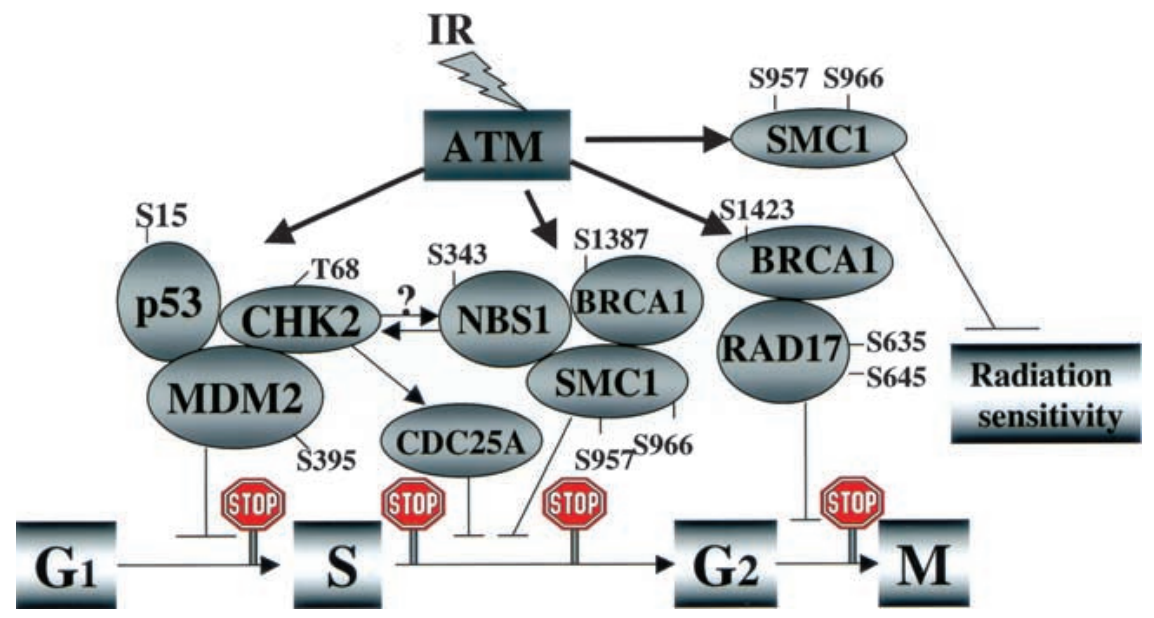
the Chk2/Cdc25A axis to Nbs1/Brcal/Smc1 in controlling the S phase checkpoint remains to be clarified. On the basis of the data shown here, phosphorylation of serines 957 and 966 in Smcl are included as targets involved in the ionizing irradiation-induced S phase arrest and are also implicated in modulating radiation sensitivity.

Atm substrates. It is interesting to note that Wang et al. reported that the Brcal supercomplex (BASC) contains many of these proteins (Wang et al. 2000) and it is reasonable to speculate that it could also contain Smcl protein. Elucidation of how this complex might signal to the replication machinery and what role the multiple phosphorylation events play in the process are important insights yet to be gained. In terms of Smcl and its role in the $S$ phase checkpoint, it is interesting that the cohesin complex containing Smc1 and Smc3 has been linked to the DNA replication machinery and to the $S$ phase of the cell cycle (Toth et al. 1999; Skibbens et al. 1999).

The observed requirement for Nbs1 and Brcal proteins for optimal ionizing irradiation-induced phosphorylation of Smcl provides some mechanistic insight. Perhaps this requirement reflects a need for a protein complex involving all of these proteins to form before Atm can effectively phosphorylate Smc1. In this way, Nbs1 and/or Brcal may be acting as scaffold proteins in the BASC complex. The observation that the presence of mutated forms of these proteins are sufficient to complement Smcl phosphorylation may simply reflect that these mutants, though functionally altered, still participate in the complex. Our prior observation that the S343A mutant of Nbs1 protein, which fails to complement the ionizing irradiation-induced $\mathrm{S}$ phase checkpoint can still bind to Mre11 (Lim et al. 2000) would be consistent with this concept, as would the observation here that phosphorylation site mutants of Smc1 still bind to Smc3.

These observations add the integral chromosomal protein, Smc1, which has been linked to chromosome dynamics and recombination, to the growing list of targets of the Atm kinase. It appears to have a somewhat general role in cellular stress responses because the data link it to responses to diverse agents ranging from ionizing irradiation to UV to alkylating agents to replication arrest. In response to the agents other than ionizing irradiation, Smcl appears to be involved in stress pathways not involving Atm. These initial insights provide novel new questions to ask about molecular mechanisms involved in controlling cellular stress responses and establish a new link between DNA damage-induced signaling pathways and a chromosomal protein complex.

\section{Materials and methods}

\section{Antibodies}

Immunoblotting studies and immunoprecipitation studies used the following antibodies: Anti-Flag M2 (Sigma), anti-c-Myc, and anti-HA (Roche). The anti-Smc1 rabbit polyclonal antibody used for the initial experiments was kindly provided by Kyoko Yokomori (University of California, Irvine) and was described previously (Schmiesing et al. 1998). The anti-Smc1 antibodies used for subsequent experiments were generated by immunization of rabbits with KLH-conjugated peptides RIDRQESSRQQRK (K1; amino acids 488-500). The KLH-conjugated phosphopeptide SQEEGS[PO $\mathrm{PO}_{3}$ SQGEDS was used to generate anti-S957-p, and KLH-conjugated DSVSG $\left[\mathrm{PO}_{3}\right]$ SQRISSI was used to generate anti-S966-p. The antibodies were affinity purified by use of the corresponding peptide-conjugated gels. The phosphospecific antibodies were preincubated with the unphosphorylated peptide for $1 \mathrm{~h}$ at room temperature to remove any residual reactivity before Western blot analysis. The Atm monoclonal antibody (D16.11) was a generous gift from Tona M. Gilmer (Glaxo Wellcome).

\section{Plasmids}

Vectors that express GST-conjugated Smc1 peptides were made by cloning complementary oligonucleotides that encoded the desired peptides (14 amino acids) into the BamHI-SmaI sites of pGEX-2T (Amersham Pharmacia Biotech). To construct vectors that expressed the larger GST-Smcl protein fragments (amino acids 310-382 or 901-1000), we used PCR with Pfu polymerase to amplify the DNA encoding these regions. The amplified PCR product was digested with BamHI and SmaI and was cloned into the pGEX-4T-1 plasmid (Amersham Pharmacia Biotech). The QuikChange Site-Directed Mutagenesis kit (Stratagene) was used to generate the following Smc1 mutants: S358A, 
S358A/S360A, S957A, S966A, and S957A/S966A. To construct the Myc-tagged SMC1 expression vector, we amplified the entire coding region of SMC1 by performing PCR with the following oligonucleotides: 5'-GCTGAATTCATGGGGTTCCTGAA ACTGATTGAG-3' and 5'-TGCATGCTCGAGCTACTGCTC ATTGGGGTTGGGGTT-3'. The PCR product was digested with EcoRI-XhoI and cloned into a pCDNA3 vector that encoded c-Myc tag.

\section{In vitro kinase assays and immunoprecipitation}

In vitro kinase assays for Flag-tagged Atm were performed as described previously (Kim et al. 1999). For immunoprecipitation of endogenous Smc1, Myc-tagged Smc1, or HA-tagged Smc3, cells were irradiated with 0 or $10 \mathrm{~Gy}$ of ionizing irradiation and then lysed $1 \mathrm{~h}$ later in ice-cold lysis buffer, which consisted of $10 \mathrm{mM}$ Tris- $\mathrm{HCl}$ (pH 7.5), $100 \mathrm{mM} \mathrm{NaCl}, 5 \mathrm{mM}$ EDTA, 0.5\% NP-40, $5 \mathrm{mM} \mathrm{Na}_{3} \mathrm{VO}_{4}, 1 \mathrm{mM} \mathrm{NaF}$, and $1 \mathrm{mM}$ PMSF. After centrifugation, supernatants were incubated with anti-SMC1, anti-Myc or anti-HA antibody, respectively. After extensive washing with the lysis buffer, immunoprecipitates were analyzed by immunoblot. For lambda phosphatase treatment, immunoprecipitated Smc1 was washed with a phosphatase buffer, which consisted of $50 \mathrm{mM}$ Tris- $\mathrm{HCl}(\mathrm{pH} 7.5), 2 \mathrm{mM} \mathrm{MnCl}, 0.1$ $\mathrm{mM}$ EDTA, and $5 \mathrm{mM} \mathrm{DTT}$, and incubated with 100 units of lambda phosphatase (New England Biolabs) at $30^{\circ} \mathrm{C}$ for $30 \mathrm{~min}$.

\section{RDS assay}

Ionizing irradiation-induced inhibition of DNA synthesis was assessed as described previously (Lim et al. 2000). Cells were prelabeled by culturing them in DMEM that contained $10 \mathrm{nCi} /$ $\mathrm{mL}$ of $\left[{ }^{14} \mathrm{C}\right]$ thymidine (NEN) for $\sim 24 \mathrm{~h}$ after transfection. The medium containing $\left[{ }^{14} \mathrm{C}\right]$ thymidine was then replaced with normal DMEM, and the cells were incubated for $6 \mathrm{~h}$. Cells were irradiated, incubated for $30 \mathrm{~min}$, and then pulse-labeled with 2.5 $\mu \mathrm{Ci} / \mathrm{mL}\left[{ }^{3} \mathrm{H}\right]$ thymidine for $15 \mathrm{~min}$ (NEN). Cells were harvested, washed twice with PBS, and fixed in $70 \%$ methanol for at least $30 \mathrm{~min}$. After the cells were transferred to Whatman filters and fixed sequentially with $70 \%$ methanol and then with $95 \%$ methanol, the amount of radioactivity on the filter was assayed in a liquid scintillation counter. The measure of DNA synthesis was derived from resulting ratios of ${ }^{3} \mathrm{H}$ counts per minute $(\mathrm{cpm})$ to ${ }^{14} \mathrm{C} \mathrm{cpm}$, corrected for those cpm that resulted from channel crossover.

\section{$G_{2} / M$ checkpoint assay}

The $G_{2} / M$ checkpoint assay was assessed as described previously (Xu et al. 2001). Cells were harvested $1.5 \mathrm{~h}$ after irradiation, washed with phosphate-buffered saline (PBS), and fixed in suspension by the addition of $2 \mathrm{~mL}$ of $70 \%$ ethanol. For late $\mathrm{G}_{2}$ accumulation assays, cells were harvested $0,24,48,72 \mathrm{~h}$ after 6 Gy irradiation prior to harvesting and fixation. After fixation, the cells were washed twice with PBS, suspended in $1 \mathrm{~mL}$ of $0.25 \%$ Triton X-100 in PBS, and incubated on ice for $15 \mathrm{~min}$. After centrifugation, the cell pellet was suspended in $100 \mu \mathrm{L}$ of PBS containing $1 \%$ bovine serum albumin (BSA) and $0.75 \mu \mathrm{g}$ of a polyclonal antibody that specifically recognizes the phosphorylated form of histone $\mathrm{H} 3$ (Upstate Biotechnology) and incubated for $3 \mathrm{~h}$ at room temperature. Then, the cells were rinsed with PBS containing 1\% BSA and incubated with fluorescein isothiocyanate-conjugated goat anti-rabbit IgG antibody (Jackson ImmunoResearch Laboratories) diluted at a ratio of 1:30 in PBS containing $1 \%$ BSA. After a 30 -min incubation at room temperature in the dark, the cells were washed again, resus- pended in $25 \mu \mathrm{g} / \mathrm{mL}$ propidium iodide (Sigma) and $0.1 \mathrm{mg} / \mathrm{mL}$ RNase A (Sigma) in PBS, and incubated at room temperature for $30 \mathrm{~min}$ before the fluorescence was measured. Cellular fluorescence was measured by use of a Becton Dickinson FACSCalibur flow cytometer/cell sorter.

\section{Clonogenic assays}

Cell lines were plated in triplicate at limiting dilutions into 6-well plates, incubated for $24 \mathrm{~h}$, and then exposed to a range of doses of ionizing irradiation (0-6 Gy) followed by incubation for 2 weeks. Prior to counting colonies, cells were fixed in $95 \%$ methanol and stained with crystal violet. A population of more than 50 cells was counted as one survived colony. The mean colony counts + standard errors (S.E.) appear in the figures.

\section{Acknowledgments}

We thank Kyoko Yokomori for the human SMC1 cDNA and anti-Smc1 antibody. We thank Chris Bakkenist and Anne O'Donnell for experimental help. We gratefully acknowledge the technical assistance of Diane Woods and Margaret Reis. We thank all members of the Kastan laboratory for helpful discussions, and Yossi Shiloh for providing complemented A-T cells, Malgorzata Zdzienicka for providing the NBS1-LBI cell line, and David Livingston for providing the wild-type BRCA1 cDNA. We are grateful to Kim Nasmyth for the yeast wild-type and mutant smc1-259 strains. This work was supported by grants from the National Institutes Health (CA71387 and CA21765) and by the American Lebanese Syrian Associated Charities (ALSAC) of the St. Jude Children's Research Hospital.

The publication costs of this article were defrayed in part by payment of page charges. This article must therefore be hereby marked "advertisement" in accordance with 18 USC section 1734 solely to indicate this fact.

\section{References}

Ahn, J.-Y., Schwarz, J.K., Piwnica-Worms, H., and Canman, C.E. 2000. Threonine 68 phosphorylation by ATM is required for efficient activation of Chk2 in response to ionizing radiation. Cancer Res. 60: 5934-5936.

Banin, S., Moyal, L., Shieh, S.-Y.,Taya, Y., Anderson, C.W., Chessa, L., Smorodinsky, N.I., Prives, C., Reiss, Y., Shiloh, Y., et al. 1998. Enhanced phosphorylation of p53 by ATM in response to DNA damage. Science 281: 1674-1677.

Bao, S., Tibbetts, R.S., Brumbaug, K.M., Fang, Y., Richardson, D.A., Ali, A., Chen, S.M., Abraham, R.T., and Wang, X.-F. 2001. ATR/ATM-mediated phosphorylation of human Rad17 is required for genotoxic stress responses. Nature 411: 969-974.

Buscemi, G., Savio, Zannini, L., Micciche, F., Masnada, D., Nakanishi, M., Tauchi, H., Komatsu, K., Mizutani, S., Khanna, K., et al. 2001. Chk2 activation dependence on Nbs1 after DNA damage. Mol. Cell. Biol. 21: 5214-5222.

Canman, C.E., Lim, D.-S., Cimprich, K.A., Taya, Y. Tamai, K., Sakaguchi, K., Appella, E. Kastan, M.B., and Siliciano, J.D. 1998. Activation of the ATM kinase by ionizing radiation and phosphorylation of p53. Science 281: 1677-1679.

Falck, J., Mailand, N., Syljuasen, R.G., Bartek, J., and Likas, J. 2001. The ATM-Chk2-Cdc25A checkpoint pathway guards against radioresistant DNA synthesis. Nature 410: 842-847.

Graeber, T.G., Osmanian, C., Jacks, T., Housman, D.E., Koch, C.J., Lowe, S.W., and Giaccia, A.J. 1996. Hypoxia-mediated selection of cells with diminished apoptotic potential in solid tumours. Nature 379: 88-91. 
Hirano, T. 1999. SMC-mediated chromosome mechanics: A conserved scheme from bacteria to vertebrates? Genes \& Dev. 13: 11-19.

Jessberger, R., Podust, V., Hubscher, U., and Berg, P. 1993. A mammalian protein complex that repairs double-strand breaks and deletions by recombination. J. Biol. Chem. 268: 15070-15079.

Jessberger, R., Riwar, B., Baechtold, H., and Akhmedov, A.T. 1996. SMC proteins constitute two subunits of the mammalian recombination complex RC-1. EMBO J. 15: 4061-4068.

Kastan, M.B. and Lim, D.-S. 2000. The many substrates and functions of ATM. Nat. Rev. Mol. Cell Biol. 1: 179-186.

Kastan, M.B., Zhan, Q., El-Deiry, W.S., Carrier, F., Jacks, T., Walsh, W.V., Plunkett, B.S., Vogelstein, B., and Fornace, Jr, A.J. 1992. A mammalian cell cycle checkpoint pathway utilizing p53 and GADD45 is defective in ataxia-telangiectasia. Cell 71: 587-597.

Kim, S.-T., Lim, D.-S., Canman, C.E., and Kastan, M.B. 1999. Substrate specificities and identification of putative substrates of ATM kinase family members. J. Biol. Chem. 274: 37538-37543.

Lim, D.-S., Kim, S.-T., Xu, B., Maser, R.S., Lin, J., Petrini, J.H.J., and Kastan, M.B. 2000. ATM phosphorylates p95/nbs1 in an S-phase checkpoint pathway. Nature 404: 613-617.

Losada, A., Hirano, M., and Hirano, T. 1998. Identification of Xenopus SMC protein complexes required for sister chromatid cohesion. Genes \& Dev. 12: 1986-1997.

Matsuoka, S., Huang, M., and Elledge, S.J. 1998. Linkage of ATM to cell cycle regulation by the Chk2 protein kinase. Science 282: 1893-1897.

Maya, R., Balass, M., Kim, S.-T., Shkedy, D., Leal, J.-F.M., Shifman, O., Moas, M., Buschmann, T., Ronai, Z., Shiloh, Y., et al. 2001. ATM-dependent phosphorylation of Mdm2 on serine 395: Role in p53 activation by DNA damage. Genes \& Dev. 15: 1067-1077.

Melchionna, R., Chen, X.-B., Blasina, A., and McGowan, C.H. 2000. Threonine 68 is required for radiation-induced phosphorylation and activation of Cds1. Nat. Cell Biol. 2: 762 765.

Michaelis, C., Ciosk, R., and Nasmyth, K. 1997. Cohesins: Chromosomal proteins that prevent premature separation of sister chromatids. Cell 91: 35-45.

O'Neill, T., Dwyer, A.J., Ziv, Y., Chan, D.W., Lees-Miller, S.P., Abraham, R.H., Lai, J.H., Hill, D., Shiloh, Y., Cantley, L.C., et al. 2000. Utilization of oriented peptide libraries to identify substrate motifs selected by ATM. I. Biol. Chem. 275: 22719-22727.

Schmiesing, J.A., Ball, Jr., A.R., Gregson, H.C., Alderton, J.M., Zhou, S., and Yokomori, K. 1998. Identification of two distinct human SMC protein complexes involved in mitotic chromosome dynamics. Proc. Natl. Acad. Sci. 95: 1290612911.

Shiloh, Y. and Kastan, M.B. 2001. ATM: Genome stability, neuronal development, and cancer cross paths. Adv. Cancer Res. 83: 209-254.

Siliciano, J.D., Canman, C.E., Taya, Y., Sakaguchi, K., Appella, E., and Kastan, M.B. 1997. DNA damage induces phosphorylation of the amino terminus of p53. Genes \& Dev. 11: $3471-$ 3481.

Skibbens, R.V., Corson, L.B., Koshland, D., and Hieter, P. 1999. Ctf7p is essential for sister chromatid cohesion and links mitotic chromosome structure to the DNA replication machinery. Genes \& Dev. 13: 307-319.

Strunnikov, A.V. and Jessberger, R. 1999. Structural maintenance of chromosomes (SMC) proteins. Eur. J. Biochem. 263: 6-13.
Stursberg, S., Riwar, B., and Jessberger, R. 1999. Cloning and characterization of mammalian SMC1 and SMC3 genes and proteins, components of the DNA recombination complexes RC-1. Gene 228: 1-12.

Tibbetts, R.S., Brumbaugh, K.M., Williams, J.M., Sarkaria, J.N., Cliby, W.A., Shieh, S.Y., Taya, Y., Prives, C., and Abraham, R.T. 1999. A role for ATR in the DNA damage-induced phosphorylation of p53. Genes \& Dev. 13: 152-157.

Toth, A, Coisk, R., Galova, M., Schleiffer, A., and Nasmyth, K. 1999. Yeast cohesin complex requires a conserved protein, Ecolp (Ctf7), to establish cohesion between sister chromatids during DNA replication. Genes \& Dev. 13: 320-333.

Vogelstein, B., Lane, D., and Levine, A.J. 2000. Surfing the p53 network. Nature 408: 307-310.

Wang, Y., Cortez, D., Yazdi, P., Neff, N., Elledge, S.J., and Qin, J. 2000. BASC, a super complex of BRCA1-associated proteins involved in the recognition and repair of aberrant DNA structures. Genes \& Dev. 14: 927-939.

$\mathrm{Xu}, \mathrm{B} ., \mathrm{Kim}, \mathrm{S} .-\mathrm{T}$. , and Kastan, M.B. 2001. Involvement of Brcal in S-phase and $\mathrm{G}_{2}$-phase checkpoints after ionizing irradiation. Mol. Cell. Biol. 21: 3445-3450.

Xu, B., Kim, S.-T., Lim, D.-S., and Kastan, M. 2002. Two molecularly distinct G2/M checkpoints are induced by ionizing irradiation. Mol. Cell. Biol. 22: 1049-1059.

Zhao, S., Weng, Y.-C., Yuan, S.-S.F., Lin, Y.-T., Hsu, H.-C., Lin, S.-C.J., Gerbino, E., Song, M.-H., Zdzlenicka, M.Z., Gatti, R.A., et al. 2000. Functional link between ataxia-telangiectasia and nijmegen breakage syndrome gene products. $\mathrm{Na}$ ture 405: 473-477.

Zhou, B.-B. and Elledge, S.J. 2000. The DNA damage response: Putting checkpoints in perspective. Nature 408: 433-439.

Zhou, B.B., Chaturvedi, P., Spring, K., Scott, S.P., Johanson, R.A., Mishra, R., Mattern, M.R., Winkler, J.D., and Khanna, K.K. 2000. Caffeine abolishes the mammalian $\mathrm{G}_{2} / \mathrm{M}$ DNA damage checkpoint by inhibiting ataxia-telangiectasia-mutated kinase activity. J. Biol. Chem. 275: 10342-10348. 


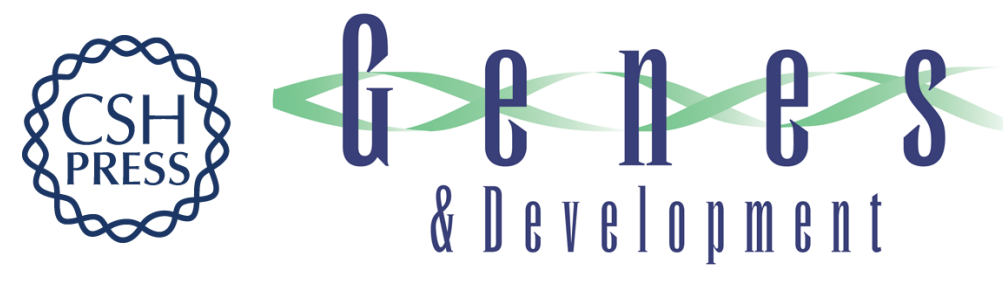

\title{
Involvement of the cohesin protein, Smc1, in Atm-dependent and independent responses to DNA damage
}

\author{
Seong-Tae Kim, Bo Xu and Michael B. Kastan
}

Genes Dev. 2002, 16:

Access the most recent version at doi:10.1101/gad.970602

$\begin{array}{ll}\text { References } & \text { This article cites } 35 \text { articles, } 20 \text { of which can be accessed free at: } \\ \text { http://genesdev.cshlp.org/content/16/5/560.full.html\#ref-list-1 }\end{array}$

License

Email Alerting Receive free email alerts when new articles cite this article - sign up in the box at the top Service right corner of the article or click here.

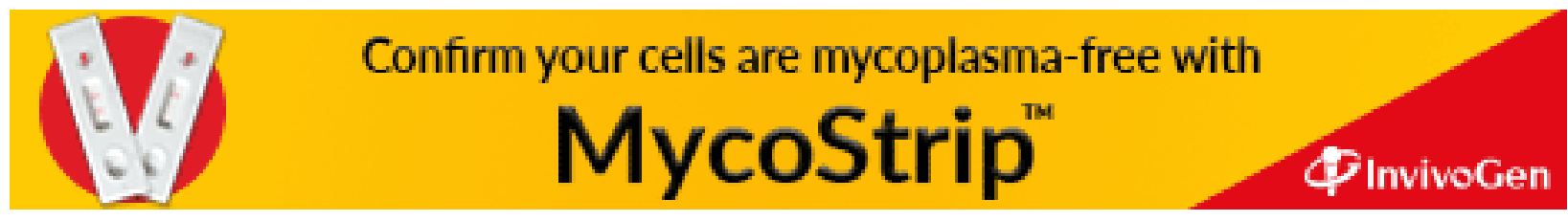

